\title{
EVALUATION OF MATURITY AND ITS CORRELATED TRAITS IN AN UNADAPTED F2 MAIZE POPULATION
}

\author{
M. S. Abdulai ${ }^{1}$, P. Y. K. Sallah ${ }^{2}$, and O. Safo-Kantanka ${ }^{3}$. \\ ${ }^{\text {I}}$ CSIR - Savanna Agricultural Research Institute, \\ P. O. Box 52, Tamale, Ghana. \\ ${ }^{2}$ CSIR - Crops Research Institute, P. O. Box 3785, Kumasi, Ghanth. \\ ${ }^{3}$ Dept of Crop Science, Kwame Nkrumah University of Science and Technology, Kumasi, Ghana.
}

\begin{abstract}
This study was conducted to understand the mode of inheritance of maturity in an adapted by unadapted $F_{2}$ maize population and to identify the best progeny of introgressed population to be used for single cross hybrid development. Thermal indices (growing degree days or heat units or thermal time), calculated from minimum and maximum temperatures, and a base temperature were used to measure the maturity of maize progenies. Two hundred and eleven (211) $S_{1}$ families developed from a cross between an adapted Corn Belt maize inbred line (B73) and an unadapted maize population and their testcrosses were evaluated in two planting dates and two locations in 1995. Maturity was quantitatively inherited as trangressive segregation for all the traits observed, and few factors were responsible for the expression of maturity in maize. Earliness was dominant to lateness. Maturity measured in thermal units was better than calendar days. Based on the performance of the test crosses up to ten SI lines could be selected for the development of single cross hybrids that could produce more grain than the check hybrids
\end{abstract}

\section{INTRODUCTION}

In maize, maturity is measured in calendar days, days from planting to anthesis, days from planting to silk emergence, days from planting to physiological maturity and percent moisture of the kernel. Thermal indices, such as, growing degree days, thermal units or thermal time have also been used (Gilmore and Rogers, 1958). The accurate prediction of time to maturity is important for the efficient exchange of genetic materials among environments (Kocster et al., 1993 and Bonhomme et al., 1994).

Most studies on the inheritance of maturity have been on the basis of days to anthesis or silking. Maize is a qualitative short-day plant as it is sensitive to day length changes in temperate re- gions. However, many cultivars are known to show no delay in flowering time under all types of day length. These cultivars are referred to as day length insensitive or are day neutral. Earlier maturity in maize tends to be dominant to lateness in the temperate areas and has relatively high heritability on individual plant and progeny bases (Hallauer, 1990). Giesbrecht (1960a; $1960 \mathrm{~b}$ ) has indicated that two to multiple genes were involved, while the data of Hallauer (1965) suggestcd that up to three factors governed days to silking in a cross between an early and a late varicty, and that additive gene action was of major importance. Using molecular marker technology, Koester et al. (1993) and Berke and Rocheficld (1995) identified QTLs controlling days to flowering and two of its correlated traits (plant 
height and total leaf number) in two near isogenic lines.

When exotic germplasm was used to improve an adapted maize population, Crossa and Gardiner (1987) reported that the cross with $50 \%$ of adapted germplasm yielded significantly less than those from the purely adapted and backcross with $75 \%$ adapted germplasm. Both the adapted and backcross populations were early maturing and yielded similarly, suggesting that major genes for lack of adaptation were acting in the cross population. Elite hybrids were also improved by the introgression of favorable alleles not already present in the hybrid (Fabrizius and Openshaw, 1994; Mejaya and Lambert, 1992). For populations, Brun and Dudley (1987) observed that those with $25 \%$ of flint germplasm was the most suitable for developing highyielding hybrids with good standability.

The objectives of this study were to understand the mode of inheritance of maturity in an adapted by unadapted $F_{2}$ maize population and to identify the best progeny of introgressed population to be used for single cross hybrid development.

\section{MATERIALS AND METHODS}

The materials used for the study included two popular Corn belt inbred lines, B73 and Mo17, and an unadapted CIMMYT population, MBITA86MRB CHILO. The CIMMYT population obtained from Dr. Mimh, an entomologist at CIMMYT has been described as having general borer resistance. The history further traced back to the University of Missouri where the initial crosses were done by crossing Mexican maize with Corn belt germplasm. Initial observations in Nebraska, and later in Florida nurseries, clearly demonstrated that some photoperiod responses existed in the CIMMYT population. In 1990, full-sib families were formed within each population, and in 1992, were observed under hot and dry conditions in Lincoln, Nebraska. During the same season, the families were ad- vanced to $S_{1}$ families. After observation of the $S_{1}$ families, a single plant, designated 2042, was selected and crossed to B73. A single (B73 x 2042) $F_{1}$ plant was self-pollinated in 1993 main season to produce $F_{2}$ seed. During the winter of 1993 the $F_{2} S$ were self-pollinated to obtain $S_{1}$ families in Florida, USA. During the summer of 1994,211 of the $S_{1}$ families were grown at Lincoln, Nebraska for observation. In addition to the observation nursery, test crosses were developed in isolation using Mol7 as the pollen donor. The $\mathrm{S}_{1}$ families were planted at Havelock on May 16 and June 13, 1995 for the first and second sowing, respectively. The season was characterized by dry spells, so the trials were irrigated when necessary. During the same season, the test crosses were evaluated at Havelock and Shelton.

An incomplete block design was used. For each trial, the initial subdivision of the experimental field was into two replications, then into incomplete field blocks with each entry appearing with a different group of entries in each of the two incomplete blocks in which it occurred (Schutz and Cockerham, 1966). Thus, no two incomplete blocks were the same. There were 27 incomplete blocks, each comprised 8 entries. The total number of entries per trial was 216, including 5 check entries. For each trial, the blocks were randomized within each replication, and the entries within each incomplete block were also randomized. One row plots each $5 \mathrm{~m}$ in length and $0.8 \mathrm{~m}$ between rows was used for the $S_{1}$ lines. Two rows per plot were used for the yield evaluation. At Shelton ( $350 \mathrm{~km}$ NW of Lincoln), the row length was increased from $5 \mathrm{~m}$ to $6 \mathrm{~m}$. Seedling establishment of the $S_{1}$ lines was good in both trials. To maintain normal plant growth during high temperatures and drought, supplemental irrigation was applied. Data were taken for the number of leaves produced at tasseling, days from planting to fifty percent pollen shed, days from planting until fifty percent of the plants produced silk, plant and ear heights. A thermal time for estimating the days from plant- 
ing to anthesis was calculated using, maximum and minimum air temperatures and a base temperature of $10^{\circ} \mathrm{C}$. The yicld trials at both Havelock and Shelton were machine harvested and the grain moisture determined electronically in the field. The grain yield in $\mathrm{Mg} / \mathrm{ha}$ was adjusted to $15 \%$ moisture. Grain yield was not recorded for the $S_{1}$ families

The data from each individual planting date for the $S_{1}$ families and individual location for the testcrosses were analyzed separately. The data for the planting dates or locations were then combined and analyzed in order to estimate the genotype by environment interaction effects using the following model,

$$
y_{i j k m}=\mu+1_{m}+r_{i(m)}+b_{i j m}+g_{i j k}+g_{i j k m}+c_{i j k m}
$$

where $y_{i j k m}$ is the observation of the $k^{\text {th }}$ entry in the $\mathrm{j}^{\text {th }}$ block of $i^{\text {th }}$ replicate in environment $\mathrm{m}, \mu$ is the mean of the observations, $l_{m}$ is the effect of $\mathrm{m}^{\text {th }}$ environment, $\mathrm{r}_{\mathrm{i}(\mathrm{m})}$ is the effect of replications within environment, $b_{i j m}$ is the effect of blocks within replications within environment, $g_{i j k}$ is the effect of entries, $g_{i j k m}$ is the entries by environment interaction and $\mathrm{e}_{\mathrm{ijkm}}$ is the random error. All the effects are assumed random, independent and normally distributed with zero means and variances due to each effect. The entries were partitioned into $S_{1}$ families, check entries and their contrast.

\section{RESULTS AND DISCUSSION}

The unadapted Mexican population used in this study contained Corn Belt germplasm and had undergone partial selection for adaptation to the Corn Belt of the USA (initial crosses were made to B73 which is a popular Corn Belt inbred line). Hence, any character not favorable to maize adaptation in the USA was selected against. Mean squares for the analysis of variance across planting dates are presented in Table 1. There were significant differences $(p<0.01)$ between the sowing dates for the maturity traits (days to pollen shed, days to silk extrusion, days from plant- ing to anthesis and thermal indices) and total number of leaves at tasseling. Planting dates did not significantly affect ear and plant heights. Significant differences $(p<0.05)$ were observed among the $S_{1}$ lines for all the traits observed. There were significant differences also among the check entries, and between the $S_{\mathrm{I}}$ lines and the check entries. $S_{1}$ families $X$ planting dates interaction effect was highly significant $(\mathrm{p}<$ 0.01 ) for days to silking and days to $50 \%$ pollen shed, thermal time, ear height and total number of leaves but not significant for plant height. Check entry X planting date interaction cffect was not significant for any of the traits measured. Unlike the $S_{1}$ lines, the check inbred lines were adapted to the conditions prevailing in $\mathrm{Nc}$ braska, and grown within the recommended time range in that environment, these lines showed similar performance. The contrast, $S_{1}$ lines versus check entries $X$ planting date interactions, was also not significant for any of the traits. The means and ranges of the traits for the families and values for the traits of the two parents (B7.3 and 2042) are presented in Table 2 . The $S_{1}$ families showed a considerable range for each trait. They exceeded the parental means for days to pollen shed, days to $50 \%$ silk extrusion, ear and plant heights, indicating that there was transgressive segregation for the maturity and its correlated characters. Therefore, segregation distortions obtained could be due to the partial selection in the unadapted population. Transgressive segregation, was attributed to additive gene action resulting from combinations of alleles conferring the character from both parents. The mean number of days from planting to $50 \%$ silking (silk extrusion) and from planting to $50 \%$ pollen shed (anthesis) were 77 and 76 for the first planting date, and 64 and 63 for the second planting, respectively. The range or period within which the plants flowered for the two sowing dates were 13 and 15 days for the first and second planting dates, respectively. The difference between the date of sowing of the trials (May 16 and June 13) was 28 days, but the dif- 
ference between their mean flowcring dates was 10 days. The anthesis-silking interval (ASI) for the first planting was $\%$ cro, while that of the second planting was two. The delayed planting resulted in delaycd silking which could account for lower grain production (Ribaut et al., 1996) due to reduced pollen production as well as poor stigma reception. It took longer for the carlicr sowing plants to flower. This suggests that the genotypes had some factor that caused them to tend to flower about the same time irrespective of time of planting. The factor was thought to bc photoperiodic effect. The mean thermal indices were 1021 and $935^{\circ} \mathrm{C}$ days for the first and second sowing, respectively. The ranges for the two sowings were 230 and 251 . respectively. The difference between the sowings for $50 \%$ pollen shed was 13 days and that for thermal index was $86^{\circ} \mathrm{C}$ days. A delay of 13 days in flowering can adversely affect the development of maize. From the formula used to estimate thermal indices in this rescarch, $86^{\circ} \mathrm{C}$ days is insignificant. Therefore, thermal indices used for measuring maturity might be better than calendar days in temperate environments.

Heritability $\left(\mathrm{h}^{2}\right)$ is the proportion of the total phenotypic variation expressed among genotypes that can be attributed to genetic differences among them. The genotypic variance could not be partitioned into additive and dominance variance. Therefore, the heritability of a trait was estimated as the ratio between the genotypic variance and the total phenotypic variance. The broad sense heritability estimates for the maturity characters obtained were between 0.50 and 0.70 (Table 4). This range is within the limits of previous studies compilcd by Hallauer and Miranda (1988). From the heritability estimates there was still a lot of chance for manipulating the families to develop superior inbred lines based on the maturity traits and the correlated oncs, except the number of leaves at flowering. The heritability for number of leaves was 0.33 . The low figure suggests that not much could be done to improve the number of leaves. It also confirms why inbred lines usually have fewer lcaves than hybrids developed from them. Very high genetic correlation coefficients (Table 3) were obtained for the maturity characters. This was expected as effects due to pleiotropy are removed during estimation of the values. The corrclation coefficient for plant and car heights was also high. The genetic correlation coefficient between the number of days to anthesis and plant height was similar to those compiled by Hallauer and Miranda (1988) from previous experiments. Selcetion for earliness using any of the corrclated traits would be effective. The correlation between the traits of $S_{l}$ families and those of their testcrosses were generally low, but significant $(p<0.01)$ for plant height, number of leaves and maturity characters. There was a negative correlation between $S_{l}$ family total number of leaves at flowering and testcross grain yicld. This implice that those familics with fewer number of leaves at flowering combined well with Mo17 to produce superior hybrids.

Testcrosses were more vigorous, taller, had wider stalk diameters, were more uniform and carlicr in maturity. This expression of vigour was due to heterosis or hybrid vigour. The genetic basis of heterosis has been reviewed by Hallauer and Miranda (1988) as physiological stimulation and dominant favorable growth factors. Inbreeding leads to the expression of recessive delcterious genes that weaken, if they do not kill, the offsprings. So when such offsprings are mated to individuals of different heterotic groups, the recessive deleterious genes are instantly rendered ineffective, hence the progeny from such a cross becomes vigorous.

Location did not affect $(p>0.05)$ the mean height of the test crosses $(266.81 \mathrm{~cm}$ for Havelock and $269.81 \mathrm{~cm}$ for Shetton). However, in Havelock, the plants produced wider stalk diameters so there was less lodging at this location as compared to those at Shelton. These differ- 


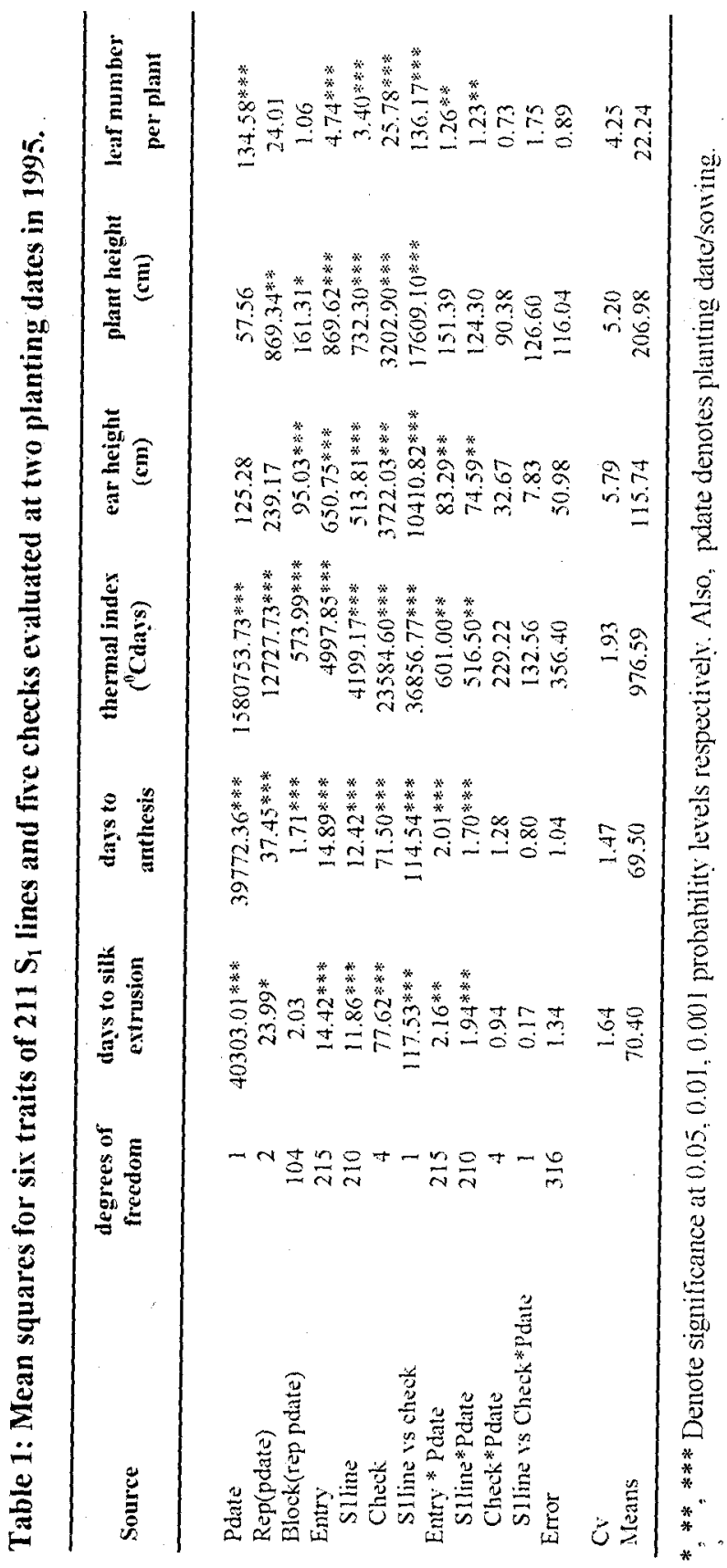


Table 2: Means and Ranges of $B 73,2042$ and $211 S_{1}$ lines for six Quantitative Traits Observed Across Planting Dates

\begin{tabular}{lllllll}
\hline & $\begin{array}{l}\text { Days to } \\
\text { Silking }\end{array}$ & $\begin{array}{l}\text { Days to } \\
\text { Anthesis }\end{array}$ & Thermal Index & Ear Height & Plant Height $\begin{array}{l}\text { Leaf Number } \\
\text { Per Plant }\end{array}$ \\
\hline $\mathrm{B} 73$ & 67.50 & 67.00 & 931.09 & 93.75 & 177.55 & 19.75 \\
2042 & 75.00 & 73.75 & 1053.17 & 124.50 & 196.00 & 23.50 \\
S1 lines & $70.46 \pm 0.25$ & $69.56 \pm 0.25$ & $977.65 \pm 2.01$ & $116.35 \pm 0.49$ & $207.80 \pm 0.62$ & $22.31 \pm 0.05$ \\
Ranges & $57.00-85.00$ & $55.00-84.00$ & $791.01-1155.57$ & $58.00-170.00$ & $130.00-257.00$ & $16.00-26.00$ \\
\hline
\end{tabular}

Table 3: Phenotypic correlation coefficients (upper figures) and genetic correlation coefficients (lower figures) for $211 \mathrm{~S}_{1}$ lines evaluated in two planting dates

\begin{tabular}{ccrrrrr}
\hline TRAITS & $\begin{array}{c}\text { Days to } \\
\text { Anthesis }\end{array}$ & \multicolumn{1}{c}{$\begin{array}{c}\text { Thermal } \\
\text { Index }\end{array}$} & Ear Height & Plant height & No of leaves \\
\hline Days to silking & $0.987^{* * *}$ & $0.8593^{* * *}$ & $0.0777^{*}$ & $0.0704^{*}$ & $0.3626^{* * *}$ \\
& 0.8943 & 0.8957 & 0.4312 & 0.3899 & 0.6486
\end{tabular}

Days to anthesis

$0.8987 * * * \quad 0.1028 * *$

$0.0818^{*}$

$0.3763 * * *$

0.9083

0.5377

0.3814

0.7391

Thermal index

$0.2662 * * *$
0.5261

$0.1985^{* * *}$

$0.4787^{* * *}$

0.3728

0.7071

Ear height

$0.7411^{* * *}$

$0.4133^{* * *}$

0.8320

0.0995

Plant height

$0.3629^{* * *}$

$*, * *, * * *$, denote significance at $0.05,0.01,0.001$ probability levels, respectively. 
Table 4: Variance components and broad sense heritability estimates for some traits of $S_{1}$ lines

TRAIT

Days to silk extrusion

Days to anthesis

Thermal index

Ear height

Plant height

Number of leaves

$\sigma_{g}^{2} \quad \sigma_{g e}^{2}$

2.46

2.67

916.86

109.50

150.39

0.54
0.31

0.34

83.54

11.38

4.97

0.17

$$
\sigma^{2}
$$

1.29

1.02

346.48

51.78

114.85

0.91 $\sigma_{p}^{2}$

4.06

4.03

1346.88

172.66

270.21

1.62 $h^{2}$

Table 5: Means of traits of $S_{1}$ families, tescrosses and hybrid checks across environments

\begin{tabular}{llll}
\hline \multicolumn{1}{c}{ Trait } & \multicolumn{1}{c}{$\mathrm{S}_{1}$} & \multicolumn{1}{c}{ Test crosses } & Hybrid checks \\
\hline Days to silk Extrusion & $70.49 \pm 2.43$ & $74.28 \pm 0.18$ & $72.95 \pm 1.39$ \\
Days to anthesis & $69.51 \pm 2.39$ & $73.36 \pm 0.18$ & $72.30 \pm 1.35$ \\
Thermal index & $976.70 \pm 33.65$ & - & - \\
Ear height & $115.70 \pm 4.00$ & $150.41 \pm 0.47$ & $131.00 \pm 3.71$ \\
Plant height & $207.00 \pm 7.15$ & $268.47 \pm 0.42$ & $261.80 \pm 2.98$ \\
Number of leaves & $22.24 \pm 0.77$ & - & - \\
Grain yield & - & $6.92 \pm 0.10$ & $7.25 \pm 0.92$ \\
Grain moisture & & $14.45 \pm 0.05$ & $13.38 \pm 0.31$ \\
\hline
\end{tabular}


ences in plant size was attributed to more appropriate maize growing environment observed at Havelock. Testcross entries $X$ location interaction was significant $(\mathrm{p}<0.01$ ) only for grain yield and percent moisture at harvest. The male parent was Mol7 so the test crosses were $50 \%$ similar in genome composition. The other variable portion having come from cach. $S_{1}$ family. Therefore, it is likely that the significant $(\mathrm{p}<$ $0.05)$ differences detected for the grain yield and percent grain moisture at harvest could be due to the alleles from the $S_{I}$ families. The check hybrids $X$ location interaction was significant $(\mathrm{p}<$ 0.01 ) for days to $50 \%$ silk extrusion, days to pollen shed and ear height. The check hybrids were commercial hybrids that were bred for adaptation to different parts of the USA. The significant interaction between the check entries and the environments showed that the hybrids responded differently in the two environments. Even though, the contrast between the check hybrids and testcrosses was not significant ( $p<$ 0.05 ), the mean grain yield of the check hybrids was $7.25 \mathrm{Mg} / \mathrm{ha}$ whereas that of the testcrosses was $6.92 \mathrm{Mg} / \mathrm{ha}$ (Table 5). Up to ten testcrosses produced more grain than any of the check hybrids. The presence of transgression for the maturity traits (days to flowering and thermal indices) suggested that the expression of maturity is controlled by several factors. Based on the performance of the test crosses and the heritability of the maturity and its correlated traits, single cross hybrids developed from inbred lines from the $S_{1}$ families will be superior to the check hybrids used in this study.

\section{ACKNOWLEGEMENT}

The senior author cxpresses sincerc appreciation to Dr. Shawn M. Kaeppler of the Agronomy Department of the University of WisconsinMadison, for supervising the planning and conducting the trials in Nebraska, USA. Many thanks to colleagues at the Savanna Agricultural Research Institute for proof-reading the manuscript.

\section{REFERENCES}

Berke, T. G. and Rocheford T. R. (1995). Quantitative Trait Loci for Flowering, Plant and Ear Height and Kerncl Traits in Maize. Crop Sci. 35: 1542 - 1549.

Bonhomme, R., Dericux, $M$. and Edmeades $G$. O. (1994). Flowering of diverse maize cultivars in relation to temperature and photoperiod in multilocation trials. Crop Sci. 34: $156-164$

Brun, E. L., and Dudley, J. W. (1987). Breeding potential in the USA and Argentina of corn populations containing different proportions of flint and dent germplasm. Crop Sci. 29: $570-577$.

Crossa, J. and Gardiner, C. O. (1987). Introgression of exotic germplasm for improving an adapted maize population. Crop Sci. 27:187-190.

Fabrizius, M. A. and Openshaw, S. J. (1994). Methods to evaluate populations of alleles to improve an elite hybrid. Theor Appl Genet 88: 653-661.

Giesbrecht. J. (1960a). The inheritance of maturity in maize. Can. J. Plant Sci. 40: 490499 .

Giesbrecht, J. (1960b). The inheritance of time of silking and pollen shedding in maize.

Can. J. Genet. Cylol. 1: $329-338$.

Gilmore, E. C. and, Rogers, J. S. (1958). Heat units as a method of measuring maturity in corn. Agron. J. 50:611 - 615 .

Hallauer, A. R. (1965). Inheritance of flowering in maize. Genetics 52:129-137.

Hallauer, A. R. (1990). Methods used in developing maize inbreds. Maydica 35: 1-16.

Hallawer, A. R. and Miranda, J. B. (1988). Quantitative genetics in maize breeding. Iowa Statc university Press, Amcs, lowa.

Koester, R. P., Sisco, P. H. and Stuber, C. W. (1993). Identification of Quantitative. Trait Loci. Controlling Plant height in Two Near 
Isogenic Lines of Maize. Crop Sci. 33: $1209-1216$.

Lin, Y. R, Scherz, K. F. and Paterson, A. H. (1995). Comparative analysis of QTLs affecting plant height and maturity across the Poaccac, in reference to an interspecific sorghum population. (enetics 141: $391-411$.

Mcjaya, M. J. and R. J. Lambert, R. J. (1992). Improving performance of adapted corn hybrid using exotic inbred. Indo. J. Crop Sci. 7: $55-62$.

Ribaut, J. M., Hoisington, D. A., Deusch, J. A., Jiang, C. and Gonzalez-de-Leon, D. (1996). Identification of quantitative trait loci under drought conditions in tropical maizc. 1. Flowcring parameters and the anthesissilking interval. Theor Appl Genet 92: 905914.

Schutz. W. M., and Cockerham, C. C. (1966). The effect of ficld blocking on gain from selection. Biometries. 22:843 - 863. 